\title{
DOES THE POPULATION LIVING IN ROMA SETTLEMENTS DIFFER IN PHYSICAL ACTIVITY, SMOKING AND ALCOHOL CONSUMPTION FROM THE MAJORITY POPULATION IN SLOVAKIA?
}

\author{
Ingrid Babinská ${ }^{1}$, Andrea Madarasová Gecková1,2, Peter Jarčuška3, Daniel Pella ${ }^{3}$, Mária Mareková4, Gabriela \\ Štefková́, Zuzana Dankulincová Veselská1; HepaMeta Team* \\ ${ }^{1}$ Health Psychology Unit, Department of Public Health, Faculty of Medicine, P. J. Šafárik University in Košice, Košice, Slovakia \\ ${ }^{2}$ Olomouc University Social Health Institute, Palacký University in Olomouc, Olomouc, Czech Republic \\ ${ }^{31} 1$ st Department of Internal Medicine, Faculty of Medicine, P. J. Šafárik University in Košice, Košice, Slovakia \\ ${ }^{4}$ Department of Medical and Clinical Biochemistry and LABMED, Faculty of Medicine, P. J. Šafárik University in Košice, Košice, Slovakia \\ ${ }^{5}$ Department of Nursing Care, Faculty of Medicine, P. J. Šafárik University in Košice, Košice, Slovakia
}

\section{SUMMARY}

Background: Several studies have revealed a high prevalence of risk factors associated with unhealthy lifestyle among individuals with lower socioeconomic status. In Slovakia, one of the most socially and health-disadvantaged groups is the Roma minority. The aim of this study is to explore differences in physical activity, smoking and alcohol consumption between the population living in Roma settlements and the majority population in Slovakia.

Methods: Data from the cross-sectional epidemiological HepaMeta study conducted in Slovakia in 2011 were used. The sample consisted of 452 Roma (mean age $=34.7 ; 35.2 \%$ men) and 403 non-Roma (mean age $=33.5 ; 45.9 \%$ men) respondents. The differences in health-related behaviour between the population living in Roma settlements and the majority population were analysed using logistic models separately for males and females.

Results: These data show a clear difference between the population living in Roma settlements and the majority population with regard to leisure-time physical activity (only in women) and smoking, although not alcohol consumption. The prevalence of leisure-time physical activities such as walking or some other type of sport was significantly lower among Roma women than among non-Roma women. Men and women living in Roma settlements are more likely to smoke on a daily basis and they are heavier smokers in comparison with the majority population. HepaMeta study did not find differences in alcohol consumption between the Roma and non-Roma men. However, Roma women reported less frequent recent drinking and binge-drinking of 6 or more doses of alcohol on a single occasion.

Conclusion: The higher prevalence of unhealthy lifestyle activities among Roma seem to contribute to these inequalities in cardiovascular diseases morbidity and mortality in comparison with the majority population.

Key words: Roma, lifestyle, smoking, physical activity, alcohol consumption

Address for correspondence: I. Babinská, Health Psychology Unit, Department of Public Health, Faculty of Medicine, P. J. Šafárik University in Košice, Tr. SNP 1, 04001 Košice, Slovakia. E-mail: ingrid.babinska@upjs.sk

\section{INTRODUCTION}

The relationships between cardiovascular diseases and risk factors such as physical inactivity, smoking and alcohol consumption are known from many studies (1-5). Furthermore, these modifiable risk factors are also associated with other chronic diseases, including diabetes mellitus, obesity, some cancers, bone and joint diseases, and depression (6-10).

A higher prevalence of the above mentioned risk factors is generally associated with lower socioeconomic status (11-15). Several studies have found that racial/ethnic minorities and individuals with lower socioeconomic status engage in less leisure-time physical activity, while occupational physical activity is more

\footnotetext{
*HepaMeta Team members are listed in Appendix
}

prevalent among these groups (16-18). Socioeconomic inequalities in leisure-time and occupational physical activity among adults are visible throughout Europe (16). Inverse relationship between level of education and leisure-time physical activity was found in almost all 12 European countries that had participated in the EUROTHINE project (19). Similarly, smoking in Europe as a whole is more prevalent among those with lower levels of education (13). Many published studies have shown a significant relationship between regional socioeconomic indicators (high proportion of manual workers and the unemployed, level of urbanisation) and mortality associated with alcohol consumption in middle age (20-22). Rosičová et al. (23) found in their work that unemployment and low education are important factors that affect regional differences in alcohol-related mortality in men in Slovak districts.

In Slovakia, one of the most socially disadvantaged groups is the Roma minority. This group has a strong accumulation of socioeconomic disadvantage, including low educational level, 
high unemployment rate, poverty, and high degree of territorial segregation $(24,25)$. It can be expected that these unfavourable conditions may cause some Roma, especially those living in Roma settlements, to be particularly susceptible to an unhealthy lifestyle (26, 27). Epidemiological and metabolic studies have revealed a high prevalence of disease-related risk factors specific for unhealthy lifestyles, such as metabolic syndrome, diabetes mellitus and cardiovascular diseases among Roma (28-30). In addition, the prevalence of smoking is reported to be higher in Roma communities (29-33). Very little information is available on leisure-time physical activity as well as information about alcohol consumption among Roma.

The aim of this study is to explore differences in physical activity, smoking and alcohol consumption between the population living in Roma settlements and the majority population in Slovakia.

\section{MATERIALS AND METHODS}

Data from the cross-sectional population-based HepaMeta study conducted in Slovakia in 2011 were used. The project aimed to map the prevalence of viral hepatitis $\mathrm{B} / \mathrm{C}$ and metabolic syndrome in the population living in separated and segregated Roma settlements and to compare it with the occurrence of the same health indicators in the majority population, while considering selected risk and protective factors of these health indicators.

The sample consisted of 452 Roma recruited by local Roma community workers and 403 non-Roma randomly selected from a list of patients from general practitioners. Data of physical activity, smoking and alcohol consumption were collected via questionnaire. For the majority population, trained assistants were present in the outpatient clinic to assist with questionnaires, if needed. In Roma respondents, questionnaires were administered in community centres by community workers or trained assistants who provided help in case of limited literacy; this seemed to have the smallest impact on the data validity (34). Methodology used in this study is described in detail elsewhere (35).

Physical activity was measured by asking respondents two questions $(35,36)$. Respondents were asked what physical activity they had done during the last week and how often they perform physical activity lasting at least 30 minutes, during which they became breathless or sweaty. Those who reported being physically active 2 or more times a week were considered to be sufficiently physically active.

Respondents were asked if they currently smoke cigarettes, cigars, pipes, or tobacco. If they did smoke, they were then asked how many cigarettes had they smoked during the day before. The answers to the first question were dichotomised: I smoke daily/I'm not a daily smoker. The answers to the second question were also dichotomised: Smoking 6 or more cigarettes the day before/Smoking less than 6 cigarettes the day before $(37,38)$.

In the case of alcohol consumption, the focus was on bingedrinking and the amount of alcohol consumed the day before. Respondents were asked how often they drink 6 or more doses of alcohol ( 1 dose $=0.5$ litres of beer, 0.2 litres of wine or 0.05 litres of spirits) on one occasion $(36,39)$. The responses to this question were dichotomised for logistic regression in two ways. Firstly, the responses regarding drinking 6 or more doses of alcohol on one occasion were dichotomised: never/6 or more doses of alcohol always. In the second dichotomisation were created two categories: 6 or more doses of alcohol less than once a month /6 or more doses of alcohol once a month or more. The responses to the question about the amount of alcohol consumed the day before were dichotomised: I did not drink/drinking 1 or more doses of alcohol the day before.

The differences in health-related behaviour between the population living in Roma settlements and the majority population in Slovakia were analysed using logistic models separately for males and females. The analyses were performed with IBM SPSS Statistics 20.

\section{RESULTS}

The final sample comprised 452 Roma (mean age $=34.47$; $\mathrm{SD}=9.16 ; 35.2 \%$ men) and 403 (mean age $=33.47$;D $=7.41$; 45.9\% men) non-Roma respondents.

Table 1 shows the prevalence of variety of physical activities performed during the last week and the odds ratio (adjusted for age) of engaging in these physical activities between the population living in Roma settlements and the majority population. Physical activity at work was reported by $21.4 \%$ of men and $18.1 \%$ of women living in Roma settlements, but by $41.6 \%$ of men and $25.2 \%$ of women from the majority population. The differences were significant for both genders (OR/CI: 0.37/0.23-0.60 men, 0.56/0.36-0.87 women). Physical work around the house or at home was reported by more respondents living in Roma settlements in comparison with the majority population $(66.7 \%$ vs. $62.2 \%$ men, $82.6 \%$ vs. $67.9 \%$ women), however, the differences were significant only for women. Roma women had a 2-times higher chance of reporting physical work around the house or at home in comparison with non-Roma women (OR/ CI: 2.15/1.39-3.34). On the other hand, women living in Roma settlements, in comparison with non-Roma women, reported less frequent engagement in aerobic activity, such as brisk walking ( $18.8 \%$ vs. $41.7 \%)$ or other sports (5.5\% vs. $20.6 \%$ ). For men, these differences were not significant, but the chance of reporting recent dancing was more than 6-times higher among Roma men in comparison with non-Roma men (OR/CI: 6.45/1.83-22.68). The population living in Roma settlements, in comparison with majority population, more frequently reported engaging in physical activity lasting at least 30 minutes during which they became breathless or sweaty 2 or more times a week, but the differences were significant only for women (OR/CI: 1.86/1.28-2.71).

Table 2 shows the behaviour of the Roma population concerning tobacco and alcohol consumption in comparison with the majority population. Nearly half of Roma reported daily smoking (54.7\% men, $44.4 \%$ women). Roma men had a 3.7-times higher likelihood of being a daily smoker (OR/CI: 3.74/2.35-5.96) and Roma women 4-times higher (OR/CI: 4.02/2.58-6.26). Significant differences were also found in the amount of cigarettes consumed. Consumption of 6 or more cigarettes the day before was reported by $44.6 \%$ of Roma men vs. $21.4 \%$ of non-Roma men, and $36.4 \%$ of Roma women vs. $10.9 \%$ of non-Roma women. In contrast with tobacco consumption, we found no significant differences in alcohol consumption between Roma and non-Roma men. Moreover, Roma women have a lower chance of consumption of 6 or more doses of alcohol on every occasion (OR/CI: 0.60/0.39-0.94) and a 
Table 1. Type and frequency of physical activity of the population living in Roma settlements in comparison with the majority population (prevalence, OR, CI)

\begin{tabular}{|c|c|c|c|c|c|c|}
\hline & \multicolumn{3}{|c|}{ Male } & \multicolumn{3}{|c|}{ Female } \\
\hline & $\begin{array}{c}\text { Roma } \\
(\mathrm{N}=159) \\
\mathrm{n}(\%)\end{array}$ & $\begin{array}{c}\text { non-Roma } \\
(\mathrm{N}=185) \\
\mathrm{n}(\%)\end{array}$ & OR (95\% Cl) & $\begin{array}{c}\text { Roma } \\
(\mathrm{N}=293) \\
\mathrm{n}(\%)\end{array}$ & $\begin{array}{c}\text { non-Roma } \\
(\mathrm{N}=218) \\
\mathrm{n}(\%)\end{array}$ & OR (95\% Cl) \\
\hline Physical activity at work & $34(21.4)$ & $77(41.6)$ & $0.37(0.23-0.60)^{\star \star \star}$ & $53(18.1)$ & $55(25.2)$ & $0.56(0.36-0.87)^{*}$ \\
\hline $\begin{array}{l}\text { Physical work around the house } \\
\text { or home }\end{array}$ & $106(66.7)$ & $115(62.2)$ & $1.19(0.76-1.87)$ & $242(82.6)$ & $148(67.9)$ & $2.15(1.39-3.34)^{\star \star \star}$ \\
\hline Brisk walking & $25(15.7)$ & $37(20.0)$ & $0.71(0.40-1.24)$ & $55(18.8)$ & $91(41.7)$ & $0.28(0.18-0.42)^{\star \star \star}$ \\
\hline Dancing & $16(10.1)$ & $3(1.6)$ & $6.45(1.83-22.68)^{\star \star}$ & $54(18.4)$ & $28(12.8)$ & $1.47(0.89-2.43)$ \\
\hline Sport & $40(25.2)$ & $56(30.3)$ & $0.80(0.50-1.30)$ & $16(5.5)$ & $45(20.6)$ & $0.22(0.12-0.40)^{\star \star \star}$ \\
\hline No physical activity & $18(11.3)$ & $16(8.6)$ & $1.27(0.62-2.59)$ & $29(9.9)$ & $16(7.3)$ & $1.39(0.73-2.66)$ \\
\hline $\begin{array}{l}\text { Physical activity } 2 \text { or more times } \\
\text { a week }\end{array}$ & $110(71.0)$ & $112(62.9)$ & $1.48(0.93-2.36)$ & $199(69.3)$ & $110(53.4)$ & $1.86(1.28-2.71)^{\star \star}$ \\
\hline
\end{tabular}

${ }^{*} p<0.05,{ }^{* *} p<0.01,{ }^{* * *} p<0.001$, the non-Roma population is the reference group for logistic regression

Table 2. Smoking and drinking behaviour of the population living in Roma settlements in comparison with the majority population (prevalence, $\mathrm{OR}, \mathrm{Cl}$ )

\begin{tabular}{|c|c|c|c|c|c|c|}
\hline & \multicolumn{3}{|c|}{ Male } & \multicolumn{3}{|c|}{ Female } \\
\hline & $\begin{array}{c}\text { Roma } \\
(\mathrm{N}=159) \\
\mathrm{n}(\%)\end{array}$ & $\begin{array}{c}\text { non-Roma } \\
(\mathrm{N}=185) \\
\mathrm{n}(\%)\end{array}$ & OR (95\% Cl) & $\begin{array}{c}\text { Roma } \\
\text { (N=293) } \\
n(\%)\end{array}$ & $\begin{array}{c}\text { non-Roma } \\
(\mathrm{N}=218) \\
\mathrm{n}(\%)\end{array}$ & OR (95\% Cl) \\
\hline \multicolumn{7}{|l|}{ Smoking behaviour } \\
\hline Daily smoking & $87(54.7)$ & $43(23.6)$ & $3.74(2.35-5.96)^{\star \star \star}$ & $127(44.4)$ & $33(15.9)$ & $4.02(2.58-6.26)^{\star \star \star}$ \\
\hline $\begin{array}{l}\text { Smoking } 6 \text { or more cigarettes day } \\
\text { before }\end{array}$ & $70(44.6)$ & $39(21.4)$ & $2.84(1.76-4.57)^{\star \star \star}$ & $102(36.4)$ & $22(10.9)$ & $4.31(2.59-7.18)^{\star \star \star}$ \\
\hline \multicolumn{7}{|l|}{ Drinking behaviour } \\
\hline 6 or more doses of alcohol ever & $86(54.8)$ & $111(61.3)$ & $0.81(0.52-1.25)$ & $49(17.3)$ & $54(26.1)$ & $0.60(0.39-0.94)^{\star}$ \\
\hline $\begin{array}{l}6 \text { or more doses of alcohol once } \\
\text { a month or more }\end{array}$ & $56(35.7)$ & $49(27.1)$ & $1.53(0.96-2.44)$ & $19(6.7)$ & $15(7.2)$ & $0.96(0.47-1.96)$ \\
\hline $\begin{array}{l}\text { Drinking } 1 \text { or more doses of alcohol } \\
\text { day before }\end{array}$ & $18(11.4)$ & $23(12.6)$ & $0.87(0.45-1.68)$ & $6(2.1)$ & $12(5.9)$ & $0.36(0.13-0.98)^{\star}$ \\
\hline
\end{tabular}

${ }^{*} p<0.05,{ }^{* *} p<0.01,{ }^{* * *} p<0.001$, the non-Roma population is the reference group for logistic regression

lower likelihood of recent drinking of 1 or more doses of alcohol (OR/CI: 0.36/0.13-0.98).

\section{DISCUSSION}

This analysis, based on the information collected in the HepaMeta study, focuses on prominent aspects of lifestyle, such as physical activity, smoking and alcohol consumption. These data show a clear difference between the population living in Roma settlements and the majority population with regard to smoking and leisure-time physical activity (only in women), although not in the drinking of alcohol.

Physical activity includes recreational or leisure-time physical activity, transportation (e.g. walking or cycling), occupational (i.e. work), household chores, play, games, sports, or planned exercise (40). The type of physical activity can take many forms: aerobic, strength, flexibility, balance. Aerobic exercise exposures can be characterized by an interaction between bout intensity, frequency, duration, and longevity of the programme (40). Al- though physical activity levels equivalent to 2.5 hours per week of moderate-intensity activity or 1 hour per week of vigorous activity are considered an important target for population health benefits, the protective effects are expected to continue at higher levels $(41,42)$. In addition, every adult should perform activities that promote and maintain their muscular strength and endurance at least twice a week (42).

We examined leisure time physical activity, but also physical activity at work and physical activity around the house or at home. Physical activity at work was reported significantly less among Roma in comparison with the majority population. A possible explanation for this finding is the very high level of unemployment of Roma in our group, where $89.6 \%$ Roma were unemployed vs. $26.4 \%$ non-Roma (43). Examination of the variety of physical activities revealed that physical work around the house or at home was the most reported physical activity among Roma and non-Roma for both genders, but the highest among Roma women. On the other hand, the prevalence of a leisure-time physical activity, such as walking or some other sport was significantly lower among Roma women than among non-Roma women. Our 
findings are consistent with results from other studies. Popper et al. (44) indicate in their work that more than two-thirds of the adult Roma population in Slovakia does not engage in any sports or exercise during their free time, less than one-third only occasionally, and only $1.1 \%$ regularly (several times per month or per week). According to the European project "Health and the Roma Community, Analysis of the Situation in Europe”, 60\% of the Roma population in seven countries involved in the project claim no engagement in any sort of physical exercise during their free time, only $11 \%$ of the population engage in physical activity during their free time, 8\% several times per month, and 3\% several times per week (27). Surprisingly, according to the study findings, Roma more frequently reported engaging in physical activity 2 or more times per week in comparison with the majority population. This may be caused by taking into account not only leisure-time physical activity but also physical activity at work or around the house or home. He and Baker (45) reported similar findings which resulted from the high rates of work-related physical activity among individuals with less education; mean scores of total physical activity were similar across racial, ethnic and educational categories. It should be noted that in contrast to the well-documented health benefits of aerobic physical activities $(1,46,47)$, information regarding the association between occupational physical activity, heavy household chores and cardiovascular diseases and mortality are inconsistent $(16,46)$. Walking and standing at work, both aerobic activities, decreases the risk of myocardial infarction, while lifting or carrying at work or an occupational workload perceived as strenuous, increase the risk of myocardial infarction (46). Therefore, to be able to assess the effect of physical activity at work and physical activity around the house or at home on health, it is necessary to have detailed information about these activities.

There is a huge variation in cut-off points in dividing smokers/ non-smokers or heavy smokers vs. light smokers and non-smokers in various studies and mostly dependency symptoms or health consequences are considered. In this study, the group of smokers was split into category of non-smokers and light smokers vs. heavy smokers. Some studies define "light smoking” as smoking less than 6 cigarettes a day $(37,38)$. Decision on dichotomisation of smoking variable was based on the studies mentioned above as well as on data from a questionnaire based on a pilot study adjusted for population living in Roma settlements (e.g. low literacy, high frequency of smoking among adults). Nevertheless, light smoking seems to be associated with ill health consequences (CVS, lung cancer, respiratory diseases) similarly to heavy smoking (48).

This study found a significantly higher prevalence of smoking among Roma in comparison with non-Roma consistent with the findings of previous studies conducted in Slovakia $(30,44)$ and other countries (27, 31-33). More than half of Roma men in the Czech Republic (63.8\%), Greece (66.3\%), Portugal (50.0\%), Bulgaria (56.0\%), and Spain (56.5\%) smoke on a daily basis (27). There is also a high percentage of daily smokers among Roma women in the Czech Republic (53.6\%), Greece (46.8\%) and Bulgaria (35.6\%) (27). Moreover, Rambousková et al. (49) also reported a significantly higher prevalence of smoking before and during pregnancy among Roma women in comparison with non-Roma mothers. Conversely, a lower percentage of daily smokers among Roma women was found in Portugal (3.8\%) and Spain $(14.3 \%)(27,50)$.
There is no general consensus on the exact limits of moderate consumption or binge drinking and various cut off points as grams of alcohol have been suggested (39). A simple measure of consuming 6 drinks per occasion has been related to increased risk of mortality among working age male drinkers (51). Also in all countries participating in the Finbalt surveys conducted in 2000 and 2002, mean weekly consumption was higher among those who more often drank six or more portion (39).

The HepaMeta study did not confirm differences in alcohol consumption between men living in Roma settlements and nonRoma men regarding binge-drinking of 6 or more doses of alcohol on one occasion and drinking of 1 or more doses of alcohol day before. Roma women reported less frequent recent drinking of 1 or more doses of alcohol and binge-drinking of 6 or more doses of alcohol on one occasion. A comparison of the findings with the results of other studies is quite difficult since they used different indicators. According to the study findings, 35.7\% of Roma men and $6.7 \%$ of Roma women consume 6 or more doses of alcohol once a month or frequently. Gourgoulianis et al. found that $45.4 \%$ of Roma in Greece consume alcohol daily (52). According to Ostrihoňová and Bérešová, $42.3 \%$ of Roma consume alcohol more than three times a month, but their consumption of alcohol is significantly lower in comparison with the consumption of alcohol in the majority population (30). Similarly, Sudzinová et al. reported significantly lower alcohol consumption among Roma patients undergoing routine coronary angiography compared with non-Roma patients undergoing the same examination, but when adjusted for educational level, gender and age these differences were not significant (53). Proportion of the Roma living in settlements did not contribute to the regional differences in alcohol-related mortality in ecological study performed in Slovakia in 2011 (23). Conversely, in Spain, Roma women have significantly higher values of alcohol consumption than nonRoma women (50). In an anthropological study, Belák reported differences in alcohol consumption among Roma families in settlements depending on social class (54). While alcohol was consumed 3-4 times a month on different occasions in the higher Roma social groups and was usually associated with dancing, families from the lowest social levels drank frequently, depending on the financial possibilities (54). Lastly, a certain correlation between living conditions, the availability of health care and social resources and the number of households with members suffering alcohol and/or drug problems was confirmed in the European project "Health and the Roma Community, Analysis of the Situation in Europe" (27).

The differences in lifestyle may be affected by socioeconomic factors; the poor economic situation of the family constitutes limited possibilities for eating as well as physical activity. Moreover, the high degree of segregation and low social integration of the Roma minority living in settlements greatly affects their participation in physical activities outside the home (55). A different pattern of health-related behaviour may be due to historical and cultural differences: e.g., cultural myths and stereotypes as well as family traditions and values can influence perception of attractiveness in relation to weight, which ultimately may affect their willingness to accept the recommendations regarding the prevention of obesity, including lifestyle changes (55). Similarly, Roma people consider smoking as a part of their ethnic and individual identity and do not regard it as a health risk $(54,56)$. It is closely related to their 
attitude toward tobacco control measures. There is significantly lower support for such measures in the Roma population, especially policies that attempt to limit tobacco access to minors and to eliminate smoking in public places (33).

A lack of physical activity, high rates of smoking as well as unhealthy eating habits (57) probably contribute significantly to the high prevalence of low levels of HDL cholesterol (55.7\% Roma men, 75.4\% Roma women) and obesity (28.9\% Roma men, $26.7 \%$ Roma women) among the Roma who participated in the HepaMeta study (58). However, these results should be generalised with caution, as Roma are a very heterogeneous group in terms of living conditions and levels of integration. Those living in settlements are probably the most disadvantaged group among them.

The higher prevalence of unhealthy lifestyle activities among Roma contributes to inequalities in cardiovascular diseases morbidity and mortality when compared with the majority. Therefore, systematic assessment and quantification of risk factors is crucial for the development of effective strategies and interventions aimed at changing lifestyles and improving health literacy in disadvantaged groups, and also to monitor their effectiveness. However, without addressing fundamental social problems and solutions of social integration of Roma communities, the effectiveness of these preventive measures can hardly be expected.

\section{Acknowledgement}

This research was partially supported by the Research and Development Support Agency, Contract No. APVV-20-032-11 and the Agency of the Slovak Ministry of Education for the Structural Funds of EU, project CEMIO-ITMS: 26220120058 (30\%). This paper was also partially funded within the framework of the project "Social determinants of health in socially and physically disadvantaged and other groups of population" (CZ.1.07/2.3.00/20.0063) and by Roche Slovensko, s. r. o.

\section{Conflict of Interests}

None declared

\section{APPENDIX}

HepaMeta Team: Peter Jarčuška, Andrea Madarasová Gecková, Mária Mareková, Daniel Pella, Leonard Siegfried, Pavol Jarčuška, Lýdia Pastvová, Ján Fedačko, Jana Kollárová, Peter Kolarčik, Daniela Bobáková, Zuzana Veselská, Ingrid Babinská, Sylvia Dražilová, Jaroslav Rosenberger, Ivan Schréter, Pavol Kristian, Eduard Veselíny, Martin Janičko, Ladislav Virág, Anna Birková, Marta Kmet’ová, Monika Halánová, Darina Petrášová, Katarína Cáriková, Viera Lovayová, Lucia Merkovská, Lucia Jedličková, Ivana Valková

\section{REFERENCES}

1. Agarwal SK. Cardiovascular benefits of exercise. Int J Gen Med. 2012;5:541-5.

2. Warburton DER, Nicol CW, Bredin SSD. Health benefits of physical activity: the evidence. CMAJ. 2006 Mar 14;174(6):801-9.

3. Taylor RS, Brown A, Ebrahim S, Jolliffe J, Noorani H, Rees K, et al. Exercise-based rehabilitation for patients with coronary heart disease: systematic review and meta-analysis of randomized controlled trials. Am J Med. 2004 May 15;116(10):682-92.
4. Wannamethee SG, Shaper AG, Walker M. Changes in physical activity, mortality, and incidence of coronary heart disease in older men. Lancet. 1998 May 30;351(9116):1603-8.

5. Lopez A. Alcohol and smoking as risk factors. In: Chamie J, Cliquet L, editors. Health and mortality: issues of global concern. Proceedings of the Symposium on Health and Mortality; 1997 Nov 19-22; Brussels. New York: United Nations Department of Economic and Social Affairs; 1999. p. 374-411.

6. Roumen C, Blaak EE, Corpeleijn E. Lifestyle intervention for prevention of diabetes: determinants of success for future implementation. Nutr Rev. 2009 Mar;67(3):132-46.

7. Friedenreich CM, Cust AE. Physical activity and breast cancer risk: impact of timing, type and dose of activity and population subgroup effects. $\mathrm{Br}$ J Sports Med. 2008 Aug;42(8):636-47.

8. Tardon A, Lee WJ, Delgado-Rodriguez M, Dosemeci M, Albanes D, Hoover R, et al. Leisure-time physical activity and lung cancer: a metaanalysis. Cancer Causes Control. 2005 May;16(4):389-97.

9. Moayyeri A. The association between physical activity and osteoporotic fractures: a review of the evidence and implications for future research. Ann Epidemiol. 2008 Nov;18(11):827-35.

10. Teychenne M, Ball K, Salmon J. Physical activity and likelihood of depression in adults: a review. Prev Med. 2008 May;46(5):397-411.

11. Stirbu I, Kunst AE, Bopp M, Leinsalu M, Regidor E, Esnaola S, et al. Educational inequalities in avoidable mortality in Europe. J Epidemiol Community Health. 2010 Oct;64(10):913-20.

12. Roskam AJR, Kunst AE. European overview of educational disparities in diabetes and the role of obesity. In: Tackling health inequalities in Europe: an integrated approach. Eurothine: final report. Rotterdam: Department of Public Health, University Medical Centre Rotterdam; 2007. p. 385-402.

13. Mackenbach JP, Stirbu I, Roskam AJR, Schaap MM, Menvielle G, Leinsalu M, et al.; European Union Working Group on Socioeconomic Inequalities in Health. Socioeconomic inequalities in health in 22 European countries. N Engl J Med. 2008 Jun 5;358(23):2468-81.

14. Elovainio M, Ferrie JE, Singh-Manoux A, Shipley M, Batty GD, Head $\mathrm{J}$, et al. Socioeconomic differences in cardiometabolic factors: social causation or health-related selection? Evidence from the Whitehall II Cohort Study, 1991-2004. Am J Epidemiol. 2011 Oct 1;174(7):779-89.

15. Suresh S, Sabanayagam C, Shankar A. Socioeconomic status, self-rated health, and mortality in a multiethnic sample of US adults. J Epidemiol. 2011;21(5):337-45.

16. Beenackers MA, Kamphuis CBM, Giskes K, Brug J, Kunst AE, Burdorf A, et al. Socioeconomic inequalities in occupational, leisure-time, and transport related physical activity among European adults: a systematic review. Int J Behav Nutr Phys Act. 2012 Sep 19;9:116.

17. Winkleby MA, Kraemer HC, Ahn DK, Varady AN. Ethnic and socioeconomic differences in cardiovascular disease risk factors: findings for women from the Third National Health and Nutrition Examination Survey, 1988-1994. JAMA. 1998 Jul 22-29;280(4):356-62.

18. Crespo CJ, Smit E, Andersen RE, Carter-Pokras O, Ainsworth BE. Race/ ethnicity, social class and their relation to physical inactivity during leisure time: results from the Third National Health and Nutrition Examination Survey, 1988-1994. Am J Prev Med. 2000 Jan;18(1):46-53.

19. Mäkinen TE, Sippola R, Borodulin K, Rahkonen O, Kunst A, Klumbiene $\mathrm{J}$, et al. Explaining educational differences in leisure-time physical activity in Europe: the contribution of work-related factors. Scand J Med Sci Sports. 2012 Jun;22(3):439-47.

20. Mackenbach JP, Stirbu I, Roskam AJ, Schaap M, Menville G, Leinsalu $\mathrm{M}$, et al. Socio-economic inequalities in mortality and morbidity: a cross-European perspective. In: Tackling health inequalities in Europe: an integrated approach. Eurothine: final report. Rotterdam: Department of Public Health, University Medical Centre Rotterdam; 2007. p. 24-48.

21. Rehm J, Sulkowska U, Mańczuk M, Boffetta P, Powles J, Popova S, et al. Alcohol accounts for a high proportion of premature mortality in central and eastern Europe. Int J Epidemiol. 2007 Apr;36(2):458-67.

22. Blomgren J, Martikainen P, Mäkelä P, Valkonen T. The effects of regional characteristics on alcohol-related mortality - a register-based multilevel analysis of 1.1 million men. Soc Sci Med. 2004 Jun;58(12):2523-35.

23. Rosicova K, Madarasova-Geckova A, Rosic M, Speybroeck N, Groothoff JW, van Dijk JP. Socioeconomic factors, ethnicity and alcohol-related mortality in regions in Slovakia. What might a tree analysis add to our understanding? Health Place. 2011 May;17(3):701-9.

24. Vašečka M, Džambazovič R. Socio-economic situation of Romanies in Slovakia as potential migrants and asylum seekers in EU member states. Bratislava: International Organization for Migration; 2000. (In Slovak.) 
25. European Union Agency for Fundamental Rights. EU-MIDIS European Union minorities and discrimination survey [Internet]. European Union Agency for Fundamental Rights; 2009 [cited 2013 Aug 25]. Available from: http://fra.europa.eu/fraWebsite/eu-midis/index_en.htm.

26. Ringold D, Orenstein MA, Wilkens E. Roma in an expanding Europe: breaking the poverty cycle. Washington: The World Bank; 2005.

27. Fundación Secretariado Gitano. Health and the Roma community, analysis of the situation in Europe: Bulgaria, Czech Republic, Greece, Portugal, Romania, Slovakia, Spain. Madrid: Fundacion Secretariado Gitano; 2009.

28. Simko V, Ginter E. Short life expectancy and metabolic syndrome in Romanies (gypsies) in Slovakia. Cent Eur J Public Health. 2010 Mar;18(1):16-8.

29. Vozarova de Courten B, de Courten M, Hanson RL, Zahorakova A, Egyenes HP, Tataranni PA, et al. Higher prevalence of type 2 diabetes, metabolic syndrome and cardiovascular diseases in gypsies than in nongypsies in Slovakia. Diabetes Res Clin Pract. 2003 Nov;62(2):95-103.

30. Ostrihoňová T, Bérešová J. Occurrence of metabolic syndrome and its risk factors amongst a selected group of Roma inhabitants. Hygiena. 2010;55(1):7-14. (In Slovak.)

31. Peters J, Parry GD, Van Cleemput P, Moore J, Cooper CL, Walters SJ. Health and use of health services: a comparison between Gypsies and Travellers and other ethnic groups. Ethn Health. 2009 Aug;14(4):359-77.

32. Vokó Z, Csépe P, Németh R, Kósa K, Kósa Z, Széles G, et al. Does socioeconomic status fully mediate the effect of ethnicity on the health of Roma people in Hungary? J Epidemiol Community Health. 2009 Jun;63(6):455-60.

33. Paulik E, Nagymajtényi L, Easterling D, Rogers T. Smoking behaviour and attitudes of Hungarian Roma and non-Roma population towards tobacco control policies. Int J Public Health. 2011 Oct;56(5):485-91.

34. Tourangeau R, Smith TW. Asking sensitive questions: the impact of data collection mode, question format, and question context. Public Opin Q. 1996;60(2):275-304.

35. Madarasová Gecková A, Jarčuška P, Mareková M, Pella D, Siegfried L, Jarčuška P, et al.; HepaMeta Team. HepaMeta - Prevalence of hepatitis $\mathrm{B} / \mathrm{C}$ and metabolic syndrome in population living in separated and segregated Roma settlements: a methodology for a cross-sectional populationbased study using community-based approach. Cent Eur J Public Health. 2014 Mar;22 Suppl:S6-11.

36. Prättälä R, Helakorpi S, Sipilä N, Sippola R, Sääksjärvi K, editors. Social determinants of health behaviours. Finbalt health monitor 1998-2008. Helsinki: National Institute for Health and Welfare; 2011.

37. Okuyemi KS, Harris KJ, Scheibmeir M, Choi WS, Powell J, Ahluwalia JS. Light smokers: issues and recommendations. Nicotine Tob Res. 2002;4 Suppl 2:S103-12

38. Hajek P, West R, Wilson J. Regular smokers, lifetime very light smokers, and reduced smokers: comparison of psychosocial and smoking characteristics in women. Health Psychol. 1995 May;14(3):195-201.

39. Helasoja V, Lahelma E, Prättälä R, Petkeviciene J, Pudule I, Tekkel M. The sociodemographic patterning of drinking and binge drinking in Estonia, Latvia, Lithuania and Finland, 1994-2002. BMC Public Health. 2007 Sep 13;7:241

40. World Health Organization. Global recommendations on physical activity for health. Geneva: WHO; 2010.

41. World Health Organization. Global health risks: mortality and burden of disease attributable to selected major risks. Geneva: WHO; 2009.

42. Haskell WL, Lee IM, Pate RR, Powell KE, Blair SN, Franklin BA, et al.; American College of Sports Medicine; American Heart Association.
Physical activity and public health: updated recommendation for adults from the American College of Sports Medicine and the American Heart Association. Circulation. 2007 Aug 28;116(9):1081-93.

43. Madarasová Gecková A, Babinská I, Bobáková D, Dankulincová Veselská Z, Bosáková L, Kolarčik P, et al.; HepaMeta Team. Socioeconomic characteristics of the population living in Roma settlements and their association with health and health-related behaviour. Cent Eur J Public Health. 2014 Mar;22 Suppl:S57-64.

44. Popper M, Szeghy P, Sarkozy S. Health and Roma community: analysis of the situation in Slovakia. Bratislava: Partners for Democratic Change Slovakia; 2009. (In Slovak.)

45. He XZ, Baker DW. Differences in leisure-time, household, and workrelated physical activity by race, ethnicity, and education. J Gen Intern Med. 2005 Mar;20(3):259-66.

46. Fransson E, De Faire U, Ahlbom A, Reuterwall C, Hallqvist J, Alfredsson L. The risk of acute myocardial infarction: interactions of types of physical activity. Epidemiology. 2004 Sep;15(5):573-82.

47. Zheng H, Orsini N, Amin J, Wolk A, Nguyen VT, Ehrlich F. Quantifying the dose-response of walking in reducing coronary heart disease risk: meta-analysis. Eur J Epidemiol. 2009;24(4):181-92.

48. Schane RE, Ling PM, Glantz SA. Health effects of light and intermittent smoking: a review. Circulation. 2010 Apr 6;121(13):1518-22.

49. Rambousková J, Dlouhý P, Kř́ížová E, Procházka B, Hrnčířová D, Anděl M. Health behaviors, nutritional status, and anthropometric parameters of Roma and non-Roma mothers and their infants in the Czech Republic. J Nutr Educ Behav. 2009 Jan-Feb;41(1):58-64.

50. Carrasco-Garrido P, López de Andrés A, Hernández Barrera V, JiménezTrujillo I, Jiménez-García R. Health status of Roma women in Spain. Eur J Public Health. 2011 Dec;21(6):793-8.

51. Laatikainen T, Manninen L, Poikolainen K, Vartiainen E. Increased mortality related to heavy alcohol intake pattern. J Epidemiol Community Health. 2003 May;57(5):379-84.

52. Gourgoulianis KI, Tsoutsou P, Fotiadou N, Samaras K, Dakis D, Molyvdas PA. Lung function in Gypsies in Greece. Arch Environ Health. 2000 Nov-Dec;55(6):453-4.

53. Sudzinova A, Nagyova I, Studencan M, Rosenberger J, Skodova Z, Vargova $\mathrm{H}$, et al. Roma coronary heart disease patients have more medical risk factors and greater severity of coronary heart disease than non-Roma. Int J Public Health. 2013 Jun;58(3):409-15.

54. Belák A. Health through eyes of those excluded. A Medical-anthropological survey of Romani rural settlement in Central Slovakia [dissertation]. Prague: Charles University; 2005. (In Slovak.)

55. Lobstein T, Baur L, Uauy R; IASO International Obesity TaskForce. Obesity in children and young people: a crisis in public health. Obes Rev. 2004 May;5 Suppl 1:4-85.

56. Petek D, Rotar Pavlič D, Švab I, Lolić D. Attitudes of Roma toward smoking: qualitative study in Slovenia. Croat Med J. 2006 Apr;47(2):344-7.

57. Hijova E, Madarasova Geckova A, Babinska I; HEPA-META team. Do eating habits of the population living in Roma settlements differ from those of the majority population in Slovakia? Cent Eur J Public Health. 2014 Mar;22 Suppl:S65-8.

58. Babinska I, Dankulincova Veselska Z, Bobakova D, Pella D, Panico S Reijneveld SA, et al.; HEPA-META team. Is the cardiovascular risk profile of people living in Roma settlements worse in comparison with the majority population in Slovakia? Int J Public Health. 2013 Jun;58(3):417-25. 